\title{
Júri simulado sobre impactos ambientais e sociais da presença de catadores de materiais recicláveis em lixão
}

\author{
Simulated jury on environmental and social impacts of the presence of \\ garbage collectors of recyclable materials in dumping ground
}

\author{
Marcos Paulo Gomes Mol' ; Valdir Lamim-Guedes ${ }^{2}$
}

1 Doutor em Saneamento, Universidade Federal de Mina Gerais (UFMG), Belo Horizonte, Brasil marcos.mol@funed.mg.gov.br / ORCID https://orcid.org/0000-0002-2568-3579

2 Doutor em Educação, Universidade de São Paulo, São Paulo, Brasil - lamimguedes@gmail.com / ORCID https://orcid.org/0000-0002-5021-4176

\section{Recebido em 18/01/2018. Publicado em Dezembro/2019}

Palavras-chave:

Júri simulado.

Aprendizagem colaborativa. Impactos ambientais. Impactos sociais. Lixão.

\section{Keywords:}

Simulated jury.

Collaborative learning. Environmental impacts. Social impacts. Dumping ground.
RESUMO: Neste texto relatamos uma atividade de Júri Simulado envolvendo aspectos sociais e ambientais relacionados a catadores de materiais recicláveis que atuam em um lixão. Esta atividade foi desenvolvida durante a disciplina Saneamento Ambiental do curso de Ciências Socioambientais de uma universidade localizada no Estado de Minas Gerais. A turma era composta por 43 alunos, que foram divididos em nove grupos com diferentes papéis durante o debate, incluindo defesa, acusação, sociedade civil organizada e jurados. Durante a atividade, foram levantados diversos elementos que demonstraram a urgência de evitar que os catadores continuem trabalhando nas condições inapropriadas do lixão, desta forma, os grupos concordaram com um Termo de Ajustamento de Conduta para que a prefeitura, com o apoio de outros atores, consiga fornecer melhores condições de trabalho para os catadores. A atividade permitiu que os participantes percebessem a posição de outros papéis, assim como a complexidade da situação tratada, sendo uma oportunidade de experimentar uma situação bastante real que estes profissionais podem se deparar no exercício profissional.

ABSTRACT: In this paper we report a Simulated Jury activity involving social and environmental aspects related to recyclable garbage collectors working in a dumping ground. This activity was developed during the Environmental Sanitation module of the Socioenvironmental Sciences course of a university located in the State of Minas Gerais (Brazil). The class was composed of 43 students, who were divided into nine groups with different roles during the debate, including defense, prosecution, organized civil society and jurors. During the activity, several elements were raised that demonstrated the urgency of avoiding that the collectors continue working in the inappropriate conditions of the dumping ground, in this way, the groups agreed with a Term of Adjustment of Conduct so that the city hall, with the support of other actors, can provide better working conditions for garbage collectors. The activity allowed the participants to perceive the position of other roles, as well as the complexity of the situation treated, being an opportunity to experience a very real situation that these professionals can come across in the professional exercise. 


\section{INTRODUÇÃO}

As questões socioambientais assumiram um papel relevante em nossas vidas, devido à relação destes com a qualidade de vida, desta forma, o ambientalismo é um movimento social dinâmico que responde a diferentes pressões como problemas ambientais em si e a relação destes com a vida em sociedade. Martínez-Alier (2014) distingui três correntes pertencentes ao ambientalismo: (1) "culto à vida silvestre", que não questiona o crescimento econômico, visando a proteção das áreas naturais intactas; (2) "evangelho da ecoeficiência", cuja atenção está voltada para os impactos ambientais e riscos à saúde devido à atividade industrial, urbanização e agropecuária, que adota conceitos como modernização ecológica, recursos naturais, capital natural e serviços ambientais, sendo esta a corrente mais forte e amplamente distribuída atualmente; (3) “justiça ambiental” ou "ecologismo dos pobres”, que é contraposta às outras duas correntes, e está relacionada aos conflitos ambientais em nível local, regional e global devido ao crescimento econômico e desigualdade social. MartínezAlier (2014, p. 34), introduz esta corrente ao tratar de uma divisão internacional entre países pobres que exportam recursos naturais e países ricos que importam tais recursos, sobre a qual afirma que $o$

resultado em nível global é que a fronteira do petróleo e do gás, a fronteira do alumínio (...) do eucalipto e do óleo de palma, (...) da soja transgênica... todas avançam na direção de novos territórios. Isso gera impactos que não são solucionados pelas políticas econômicas ou por inovações tecnológicas e, portanto, atingem desproporcionalmente alguns grupos sociais que muitas vezes protestam e resistem (2014, p. 34).

O movimento pela justiça ambiental teve origem nos Estados Unidos nos anos 196070 e tinha relação estreita com o movimento negro, por este motivo também é chamado de "racismo ambiental". Para designar esse fenômeno de imposição desproporcional dos riscos ambientais às populações menos dotadas de recursos financeiros, políticos e de informação, e/ou por características raciais, étnicas e econômicas, tem sido consagrado o termo injustiça ambiental (ACSELRAD; MELLO; BEZERRA, 2009; NEWTON, 2009), também utilizado para os que têm o acesso negado a ambientes bons (sem poluição do ar, por exemplo) ou àqueles excluídos dos processos decisórios ou de contestação (SHRADER-FRECHETTE, 2002). Como contraponto, cunhou-se a noção de justiça ambiental para denominar um quadro de vida futuro, no qual essa dimensão ambiental da injustiça social venha a ser superada (ACSELRAD; MELLO; BEZERRA, 2009), ou seja, a tentativa de alcançar a equidade ambiental para todos os grupos dentro da sociedade (NEWTON, 2009).

A noção de justiça ambiental tem sido utilizada, sobretudo, para constituir uma nova perspectiva e integrar as lutas ambientais e sociais, já que "a determinação de ambientes criados não se encontra alheia à vida social humana, mas, sim penetrada e reordenada, 
confundido o que é 'natural' com o que é 'social"' (GIDDENS, 1990 apud SIQUEIRA; MORAES, 2009, p. 2117). Neste contexto, a situação dos catadores de materiais recicláveis, antes chamados de forma pejorativa de catadores de lixo, passou a ser alvo da atenção de pesquisadores e administradores públicos apenas nos últimos 20 - 30 anos, pois até os anos 1980, “a ocupação de catador era extremamente desvalorizada, incorporava aqueles que viviam nas suas ou nos lixões como indigentes e que conviviam com urubus e tratores na busca por alimentos, roupas e materiais para vender" (FERRAZ; GOMES; BUSATO, 2009, p. 764). Segundo Ferraz, Gomes e Busato (2009, p. 763), "na tarefa de coleta, separação, manuseio e transmutação do lixo em mercadoria, encontramos o modo de sobrevivência de um novo agente, que, ao se expor a diversos riscos de acidentes e de saúde, também se encontra socialmente vulnerável”. Segundo Bosi (2008, p. 104),

\begin{abstract}
(...) a reciclagem no Brasil só tornou-se possível em grande escala quando o recolhimento e a separação dos resíduos se mostraram uma tarefa viável e de baixo custo, isto é, realizável por trabalhadores cuja remuneração compensasse investimentos de tecnologia para o surgimento do setor de produção de material reciclado. (...) Nestes termos, explica-se por que essa força de trabalho surgiu composta de trabalhadores sem contrato e com uma produtividade que pudesse ser definida pelo pagamento por produção: uma população desancada do mercado de trabalho e sem atributos para retornar às ocupações formais.
\end{abstract}

O crescimento no número de catadores deve-se ao desenvolvimento do setor industrial de materiais recicláveis, assim como, devido ao aumento do desemprego e da precarização do trabalho a partir dos anos 1990 (FERRAZ; GOMES; BUSATO, 2009). Porto et al. (2004, p. 1511), ao entrevistarem catadores que atuam no aterro de Gramacho (Duque de Caxias-RJ), encontraram que estes "percebam o lixo como fonte de sobrevivência, a saúde como capacidade para o trabalho e, portanto, tendem a negar a relação direta entre o trabalho e problemas de saúde". Assim, trata-se como uma "inclusão perversa", pois permite que estas pessoas consigam gerar renda, mas sem acesso à seguridade social, exercendo uma atividade laboral desgastante, com sérios riscos à saúde, vítimas de preconceito e excluídos de diversos ambientes sociais (MEDEIROS; MACEDO, 2006). Trata-se de uma relação paradoxal, pois um movimentado setor industrial depende do trabalho destas pessoas, mas elas não têm garantias de uma sobrevivência digna.

Apesar desta situação, em termos ambientais, "não há reciclagem sem catador" (BENVINDO, 2010, p. 71), independentemente da forma de organização, pois cerca de $90 \%$ dos materiais recicláveis que chegam às indústrias de reciclagem advêm do trabalho dos catadores. Assim, estes trabalhadores são os agentes iniciais do processo de reciclagem e, por decorrência, apresentam um papel importante para a sustentabilidade, contribuindo para a redução da extração de matérias-primas, economia da energia que seria utilizada na 
transformação e transporte das matérias-primas (o caso do alumínio tal redução é bastante acentuada) e redução do volume de resíduos encaminhados para disposição final.

O contexto desfavorável de trabalho dos catadores de materiais recicláveis é tema importante em nosso país, que deve ser reconstruído, partindo-se da mudança de opinião da sociedade. Para isso, a formação de profissionais em nível superior deve incluir momentos de reflexão e de contato com situações conflituosas como a descrita acima: um problema social, das condições de trabalho, remuneração e representação social, contraposta a um serviço essencial para a sustentabilidade. Desta forma, a discussão sobre temas socioambientais envolve a incorporação da dimensão ambiental nas universidades, situação referente ao conceito de ambientalização, isto é, a "inserção de conhecimentos, de critérios e de valores sociais, éticos, estéticos e ambientais nos estudos e currículos universitários, no sentido de educar para a sustentabilidade socioambiental” (GUERRA et al., 2015, p. 12). Tal incorporação nos currículos formais deve ser um "instrumento que estimule os indivíduos à reflexão e à ação acerca dos desafios da sustentabilidade, tem se mostrado uma tarefa bastante complexa nos mais diferentes campos de conhecimento" (DEMAJOROVIC; SILVA, 2012, p. 40).

Uma forma de implementar no ensino superior uma visão mais complexa, que retrata de forma mais real as problemáticas ambientais, é por meio de atividades educativas que envolvam debate e distintos posicionamentos sobre o problema analisado, como é a atividade de "Júri Simulado". O Júri Simulado trata-se da "reprodução de um julgamento, no qual são apresentados argumentos de defesa e de acusação para análise de um problema" (CARMO et al., 2016, p. 25), sendo, portanto, uma metodologia ativa, isto é, baseia-se em "formas de desenvolver o processo de aprender, utilizando experiências reais ou simuladas, visando às condições de solucionar, com sucesso, desafios advindos das atividades essenciais da prática social, em diferentes contextos" (BERBEL, 2011, p. 29). Desta forma, permite sua utilização em diversas situações didáticas, como ações de educação ambiental na educação básica (ALBUQUERQUE et al., 2015), para a formação inicial de professores, favorecendo que estes atuem de forma descentralizada, ao se colocarem no lugar do outro (VIEIRA et al., 2014, 2015).

Atividades de Júri Simulado são relevantes para o tratamento de temas conflituosos em sala de aula, como a construção de hidrelétricas ou de incineradores de resíduos, para citar dois exemplos da área socioambiental. Os temas controversos permitem tanto uma visão mais real da ciência, isto é, uma ação humana, sujeita a erros e a divergência entre pesquisadores, assim como pelo fato destes problemas não serem resolvidos apenas por informações 
Ensino, Saúde e Ambiente - V12 (3), pp. 202-216, Dez. 2019

técnicas, dependendo de um intenso debate social, que envolve a participação popular (REIS, 2007).

Neste texto apresentamos um relato de aplicação da dinâmica Júri Simulado no curso de graduação em Ciência Socioambientais de uma instituição de ensino superior de Mina Gerais.

\section{METODOLOGIA}

A dinâmica realizada adotando-se o "Júri Simulado" permite estimular a reflexão por meio do diálogo, propiciando aos participantes a oportunidade de desenvolver um olhar mais crítico sobre o tema em debate, partindo do pressuposto de que é imprescindível preservar o respeito às distintas opiniões e conduzir as tomadas de posição a partir de argumentos sólidos. Real e Menezes (2007) sugerem que a prática da argumentação mediante distintas posições, incluindo aquelas contrárias à que se defende, exige um trabalho de "descentração", ou seja, "o de poder refletir a partir da posição do outro" (REAL; MENEZES, 2007). Outros autores sugerem que essa dinâmica colabora com o desenvolvimento da capacidade de arguição, diálogo e confronto de ideias, uma vez que propõe a análise de um único tema pelos participantes sob diferentes pontos de vista, favorecendo na construção de opiniões críticas (CAMPOS; SILVEIRA, 2013).

A atividade de Júri Simulado foi realizada entre os dias 02 a 09 de abril de 2014 e integrou a disciplina Saneamento Ambiental de um curso de Graduação em Ciências Socioambientais de uma instituição de ensino superior localizada em Minas Gerais. A turma era composta por 43 alunos, que foram divididos em grupos com diferentes papéis durante o debate, incluindo defesa, acusação, sociedade civil organizada e jurados. Os temas foram distribuídos aleatoriamente entre os grupos, através de sorteio realizado pelo facilitador da atividade (professor).

O facilitador realizou preparação para o debate apresentando as regras de como ocorreria a dinâmica. Nesta ocasião, os alunos foram informados sobre o que se esperava para cada ator participante do Júri, tendo, portanto, dias de preparação e estudos. Opiniões prévias de alguns atores participantes do Júri eram contraditórias, de forma a incitar o debate e o exercício de se respeitar a opinião oposta. O tema selecionado foi a busca de soluções para a presença de catadores em um lixão municipal. Houve elementos suficientes para se discutir tanto as questões focadas no contexto ambiental quanto social.

O problema apresentado aos alunos na fase de preparação está descrito a seguir:

\section{Contextualização do problema}

O município Grande Vila (nome fictício) possui aproximadamente 58.000 habitantes, e está localizado em uma região com várias nascentes de um importante corpo d'água do 
Estado de Minas Gerais. Devido a divergências decorrentes do conflituoso processo político local, alguns desafios ambientais ainda não foram priorizados e superados, como é o caso da destinação final dos resíduos sólidos. No município, os resíduos ainda são dispostos em lixão, e no local há aproximadamente 32 catadores que separam resíduos com potencial de reciclagem e, para a sobrevivência, comercializam com atravessadores (compradores de produtos recicláveis dos catadores para vender a grupos que comercializam com empresas de reciclagem). Alguns catadores moram no próprio lixão, e dentre eles, existem oito crianças. Destacam-se ainda outras informações relevantes ao contexto:

- Os catadores que coletam no lixão conseguem uma receita mensal variando entre $\mathrm{R} \$ 650,00$ a $\mathrm{R} \$ 1.100,00$;

- Há uma associação de catadores existente no município desde 2005, que possui 13 associados. Eles coletam resíduos em grandes geradores, como estabelecimentos comerciais (supermercados, lojas, etc), contando com o apoio da Prefeitura apenas na disponibilização de um veículo em condições precárias para coleta dos resíduos. Receita mensal média de $\mathrm{R} \$ 900,00$ por catador. O coordenador não apresenta balanço financeiro mensal - apenas paga os associados "contratados";

- O município não possui coleta seletiva, ou seja, há uma única estrutura de recolhimento de resíduos sólidos, sendo todos encaminhados para o lixão. A Prefeitura não realiza campanhas educativas para incentivar a coleta seletiva;

- Poucas iniciativas da população são visíveis para tentar modificar o cenário de destinação de resíduos - exceção da ONG ambiental, que trabalha insistentemente para mostrar a importância da implantação da coleta seletiva;

- População não tem conhecimento da presença dos catadores no lixão, devido à localização do espaço para dispor os resíduos que é de difícil acesso;

- Estudos realizados por pesquisadores de uma conceituada universidade nacional constataram que há impactos ambientais nos corpos d'água da região, em decorrência da infiltração do chorume;

- Com a consolidação das legislações ambientais nos últimos anos, a FEAM e o Ministério Público foram acionados a avaliar o contexto do município Grande Vila, sob o ponto de vista legal;

- Pouco se sabe sobre a saúde dos catadores. Alguns relatos dos próprios catadores que sobrevivem nos lixões indicam que é comum o uso de medicamentos encontrados nos resíduos, bem como consumo de alimentos. Registraram também que alguns colegas adoecem com frequência, além de haver elevada frequência de casos de alcoolismo. A expectativa de vida é baixa, situação reconhecida pelos próprios catadores. 


\section{Definição dos grupos e das ideias a serem defendidas}

Diante do contexto apresentado, o Júri Simulado teve como objetivo avaliar a situação do município Grande Vila simulando uma reunião na Câmara Municipal, quando foram tomadas algumas importantes decisões em relação ao gerenciamento de resíduos e à situação dos catadores no município. Sendo assim, os alunos deveriam representar alguns grupos de atores que foram convidados a participar desta reunião e apresentar propostas de atuação, com foco na área de atuação específica de cada um. São eles:

1. Representantes da Secretaria Municipal de Meio Ambiente: Prefeitura Municipal, acusados de omissão diante dos problemas sociais e ambientais. Deveriam apresentar justificativas para a situação em debate, indicando rumos para solucionar os principais problemas;

2. ONG ambiental: tem atuado em questões ambientais no município, com o foco em minimizar os impactos ambientais das atividades industriais e humanas. O maior interesse foi exigir mudanças imediatas visando solucionar os problemas ambientais;

3. ONG social: tem atuado em questões sociais no município, com o foco na redução das desigualdades sociais. Atuou exigindo dos atores presentes a efetividade dos direitos sociais dos catadores, que sobreviviam em condições precárias;

4. Ministério Público: atuou na proposição de ferramentas e ações que pudessem fazer cumprir as melhorias necessárias, definindo obrigações e prazos aos atores participantes e concluindo sobre o caso debatido;

5. FEAM (Fundação Estadual de Meio Ambiente): órgão ambiental do Estado de Minas Gerais, teve como função apresentar argumentos legais para embasar o debate, especialmente o Ministério Público em sua decisão, citando as legislações ambientais;

6. Associação de catadores municipal: tiveram como principal atuação a representação dos catadores associados, em atividade no município, preocupados com a redução dos benefícios que recebem diante da formalização de uma nova associação de catadores incluindo os trabalhadores que atuam no lixão;

7. Representantes do Serviço Social da Prefeitura: Prefeitura Municipal, foram designados para responder quanto aos direitos sociais dos catadores que sobrevivem nos lixões. Deveriam fazer cumprir as ações de proteção a estes catadores, uma vez que eles não possuem representação via associações;

8. Pesquisadores de uma importante universidade nacional: convidados para colaborar com os argumentos técnicos sobre impactos à saúde decorrente da exposição aos 
Ensino, Saúde e Ambiente - V12 (3), pp. 202-216, Dez. 2019

resíduos e formas apropriadas de manejo de resíduos, incluindo questões operacionais de aterros e possíveis impactos ambientais do lixão existente;

9. Representantes da Secretaria de Saúde da Prefeitura: deveriam apresentar informações técnicas sobre os principais tipos de impacto à saúde aos catadores e prever ações de proteção aos catadores.

Todas as informações citadas acima foram discutidas em aula preparatória, de forma a orientar os alunos em relação às posições esperadas para cada ator participantes do Júri. Destaca-se que as informações deveriam nortear os grupos, sem o comprometimento da liberdade de expressão de cada aluno durante o debate.

\section{Orientações para o trabalho}

Cada grupo elaborou um documento de até uma lauda, entregue antes do debate, compilando as principais informações que sustentaram a explanação a ser feita no Júri. Além do documento, cada grupo teve 5 minutos para fazer uma breve defesa, indicando um membro do grupo para representa-los. Todos os membros do grupo foram orientados a se preparar para responder a questionamentos, que foram feitos mediador e pelos demais alunos. A cada pergunta o mediador elegia aleatoriamente algum membro do grupo para responder ao questionamento. Os alunos foram avaliados por meio de pontuação para o grupo (parte escrita e apresentação) e pontuação individual (questionamento durante o debate e arguição). A atuação do professor neste tipo de atividade é de mediador, assumindo uma posição de "scaffolding", isto é, uma postura que "implica em o professor dar suporte aos argumentos dos estudantes em prol do desenvolvimento da discussão, oferecendo oportunidades para a evolução das contraposições latentes entre argumentos científicos e do cotidiano" (BERNARDO et al., 2014, p. 364).

\section{Coleta e análise dos dados}

Os dados foram coletados durante a realização de atividades acadêmicas em sala de aula. Os registros analisados neste estudo contemplaram o documento consolidando as principais ideias da defesa que cada grupo fez no júri e os registros de anotações feitas pelo mediador durante o debate, de forma a permitir a compreensão de como transcorreu o júri simulado.

Os dados foram analisados baseando-se na Análise de Conteúdo, modalidade análise categorial, segundo proposta de Bardin (2008). As categorias de análise abarcaram os interesses de cada grupo de participantes no debate, no sentido de compreender a decisão a ser tomada: como estruturar a saída dos catadores que estavam no lixão municipal e solucionar o problema à luz do contexto ambiental e social. O encontro foi realizado na sala de aula com as cadeiras dispostas em círculo, conforme recomendado por Gaskell (2007). 


\section{RESULTADOS E DISCUSSÃO}

O Júri Simulado tem a característica importante de ser uma atividade role-play, isto é, na qual os "estudantes devem exercer uma determinada função ou papel, ou seja, eles têm que se imaginar e se colocar no lugar de um personagem, e as suas contribuições para a atividade em desenvolvimento devem ser feitas a partir da perspectiva desse papel ou função" (MCSHARRY; JONES, 2000 apud VIEIRA et al. 2014, p. 204). Para Vieira et al. (2014), o Júri Simulado é um tipo particular de role-play no qual destaca-se o papel de acusação, defesa e de juízes, assim como a possibilidade de alternar os posicionamentos (processo de descentralização) e que nem sempre o papel encenado é aquele que representa a perspectiva real do grupo. Estas duas situações refletem a relevância deste tipo de atividade, ao permitir que os educandos se coloquem no lugar do outro e percebam que a temática abordada não é simples, sendo que o posicionamento deve ser construído a partir de argumentos.

O Júri Simulado executado incentivou a discussão sobre o tema em questão, que envolvia polêmicas em torno das áreas social e ambiental. Foi criado um ambiente de inclusão e respeito das diferentes opiniões abordadas, através da mediação do professor que controlou os tempos das falas e, a todo tempo, trazia os participantes para o foco das discussões. A maior parte dos alunos demonstrou interesse na atividade, considerando a qualidade das avaliações. Alguns momentos foram marcados por discussões mais acaloradas devido à polêmica e divergência de opiniões. Considerou-se positiva a realização da atividade acadêmica, uma vez que permitiu a simulação de um caso possível de ocorrer na realidade, envolvendo a temática do curso e provocando reflexões sobre a dificuldade de consenso nas tomadas de decisão. A seguir são apresentados os posicionamentos de cada um dos grupos de alunos.

Os representantes da Secretaria Municipal de Meio Ambiente conduziram a defesa aceitando o desafio de sanar os problemas ambientais, quando questionados pela ONG ambiental. Neste caso, os conflitos foram poucos devido à postura de aceitação. O grupo da FEAM colaborou com as colocações sobre as obrigações legais, fortalecendo ainda mais as poucas opções diante do debate aos representantes da Secretaria de Meio Ambiente. Por sua vez, estes tentaram se defender sugerindo que as mudanças políticas a cada eleição comprometeram a realização de ações contínuas em defesa do meio ambiente no município. De fato, Motta e Borges (2014) relataram que mudanças de gestão e de marcos institucionais na esfera municipal podem repercutir de forma significativa na manutenção de atividades vinculadas ao gerenciamento de resíduos. 
Os representantes da universidade trouxeram argumentos técnicos para justificar a urgência de solução do lixão, reforçando a necessidade de início imediato das obras para construção do aterro sanitário. Eles citaram fontes de financiamento do governo federal que apoiam os municípios nestas soluções, e frisaram ainda a importância dos consórcios para auxiliar na viabilização financeira. Do ponto de vista acadêmico, estas citações demonstraram o bom engajamento destes alunos, que apresentaram uma visão ampla do desafio prático de acabar com os lixões no país. O moderador, ao final do Júri, retornou este assunto com o intuito de conscientizar a todos em relação ao desafio de consolidação na prática das soluções vislumbradas na teoria, em especial, em relação ao custo e desafio que representa para os municípios a obra de criação e manutenção de um aterro sanitário.

Sobre o contexto da saúde dos catadores, foram levantados diversos elementos que demonstraram a urgência de evitar que os catadores continuem trabalhando nas condições inapropriadas do lixão (CATAPRETA; HELLER, 1999; RUSHTON, 2003; PORTA et al., 2009; DOMINGO; NADAL, 2009). A proposta que chegou ao consenso foi a de criação de uma associação de catadores de materiais recicláveis exclusiva para estes trabalhadores, favorecendo na consolidação de condições dignas de trabalho. Todos os grupos concluíram por esta opção. Houve a ressalva do grupo representante dos catadores já associados, que questionaram como seria a divisão dos materiais recicláveis do município. Os representantes da Prefeitura se comprometeram em acompanhar a distribuição dos resíduos de forma justa, e fornecer apoio na consolidação da associação recém-formada e na melhor estruturação da associação existente. Nota-se que houve bom senso na decisão, que foi balizada também pelos representantes da Secretaria do Serviço Social da Prefeitura. Na literatura da área, encontramos que a criação de uma cooperativa representa várias vantagens, como demonstrado por Porto et al. (2004), que ao comparar dois grupos de catadores que atuam no aterro de Gramacho (Duque de Caxias-RJ) encontraram que os cooperados tem uma rotina de trabalho mais regular, com renda fixa e melhores condições de trabalhos, tanto pelo uso de Equipamentos de Proteção Individual, como por trabalhem em local coberto e com local para realizar refeições e vestiário, enquanto os catadores que atuam diretamente no lixão não têm estes benefícios.

Outra ação decidida durante o Júri foi o acompanhamento da saúde de todos os catadores do município, pactuado pela Secretaria de Saúde e incluindo corresponsabilidade dos membros da associação dos catadores e da ONG social. Novamente, pode-se perceber o bom senso no debate e conclusão, ainda que meramente teórica - mais uma vez a variável financeira não foi colocada em discussão devido ao pouco tempo da atividade. Esta decisão é relevante porque a vulnerabilidade social dos trabalhadores, relacionada à reduzida 
Ensino, Saúde e Ambiente - V12 (3), pp. 202-216, Dez. 2019

escolaridade e a necessidade de geração de renda, fazem com os trabalhadores associem saúde à capacidade de continuar trabalhando (PORTO et al., 2004), ignorando problemas de saúde como diarreia, verminoses e questões emocionais.

Todas as sugestões de solução foram endossadas pelos representes do Ministério Público, que optaram por propor um termo de ajustamento de conduta (TAC) ao município. Viégas et al. (2015) sugerem que, na prática, o TAC aparece como um instrumento eminentemente reativo de tratamento de conflitos, que é acionado pelos órgãos legitimados quando um problema ou dano já ocorreu, se valendo supostamente do princípio da prevenção no sentido de evitar que esses danos ocorram novamente. Portanto, a argumentação dos alunos assumiu uma postura resolutiva.

A atividade foi marcada pelo equilíbrio e respeito, apesar de alguns momentos terem sido marcados por discussões polêmicas. De forma geral, não foi perceptível a atuação dos grupos em desarticular os argumentos dos demais participantes. Possivelmente, a fase de preparação do Júri Simulado tenha sido pouco efetiva neste estímulo, que em geral, conduz a um melhor aproveitamento das discussões.

Os graduados em Ciência Socioambientais necessitam se preparar para lidar com conflitos similares ao apresentado, e desta maneira, a transdisciplinaridade e transversalidade das questões socioambientais devem estar sempre presentes ao longo do curso. Portanto, pode-se considerar que o Júri Simulado relatado neste artigo auxiliou na consolidação de conceitos importantes a estes estudantes, incluindo a capacidade de discutir e apontar a importância da construção coletiva de conceitos em processos socioambientais.

No caso da formação de profissionais da área ambiental, como é o caso da atividade descrita acima, ao se depararem com a complexidade de um julgamento, estes profissionais têm contato com situação mais próxima das reais, sendo uma forma de preparação mais relevante para estes. Conforme Bernardo et al. (2014, p. 361): "a ênfase do ensino no domínio de uma grande quantidade de conhecimentos factuais acaba sobrepujando um grande objetivo educacional: desenvolver a capacidade do sujeito de refletir e ter autonomia frente à necessidade de solucionar problemas que lhes sejam relevantes". Neste sentido, os profissionais formados no curso de Ciências Socioambientais devem aprimorar a capacidade de compreensão do contexto de vida do seu público alvo, sem a imposição de nenhum conhecimento teórico, mas buscando a incorporação de novos conteúdos ao cotidiano dos indivíduos abordados que possam colaborar com o processo de formação individual dos sujeitos abordados. Este processo remete à emancipação sugerida por Paulo Freire, que é necessária como apropriação da liberdade e, consequentemente, conquista de uma condição 
social desprovida de opressão, entendida aqui como o direito de discordar das circunstâncias e exercer o direito de pensar, agir e questionar (FREIRE, 1987).

Aliado a isto, esta atividade envolve a abordagem de um tema controverso ( $c f$. REIS, 2007). Albuquerque et al. (2013) desenvolveram um Júri Simulado envolvendo a construção de um shopping center e de uma avenida em Recife-PE com jovens de ensino médio de uma escola pública, elas observaram que os alunos, inicialmente, apresentaram apenas argumentos envolvendo a importância econômica das duas obras, mas, ao longo da atividade, passaram a perceber a complexidade da questão, por exemplo, ao perceberem que diversos pescadores que moram numa área de mangue teriam que se mudar. Assim, estes passaram a ter uma visão socioambiental, indo além da questão econômica.

Albuquerque et al. (2015) desenvolverem um Júri Simulado como ação de educação ambiental crítica. Para estas autoras, o diálogo, em ações de Júri Simulado, é usado para viabilizar que os interesses das partes envolvidas sejam atendidos de forma a termos uma situação de ganha-ganha. Desta forma, "a resolução dos conflitos se deu de forma alternativa e criativa, buscando conhecer não apenas a posição que a parte exterioriza, mas seu real interesse no caso, para tentar conciliá-lo com o real interesse da outra parte, na busca da satisfação de ambos" (ALBUQUERQUE et al., 2015, p. 207). Esta foi uma ação desenvolvida por meio de um projeto de extensão desenvolvido durante uma manhã.

É importante destacar que o Júri Simulado deve ser uma atividade integrada a ao currículo/temáticas tratados, de forma a reforçar a contextualização do ensino. De forma semelhante, a articulação com outras ações de educação ambiental reforça o aspecto crítico, emancipatório, permanente e contínuo, que devem nortear os processos de ambientalização institucional e curricular.

\section{CONSIDERAÇÕES FINAIS}

Neste texto relatamos uma ação de Júri Simulado desenvolvido durante o curso de Ciências Socioambientais de uma universidade localizada no Estado de Minas Gerais. Esta ação esteve articulada com outras desenvolvidas durante a disciplina, assim como ao longo do curso e na pesquisa de vários dos alunos participantes.

A capacidade de construção de argumentos em defesa dos diferentes papéis sugeriu a grande potencialidade desta atividade acadêmica para tratar de temas controversos e polêmicos, como foi o caso dos catadores sobrevivendo em um lixão no município fictício proposto. O exemplo debatido poderia ser a realidade de alguns dos muitos municípios brasileiros ainda sem a solução de saneamento adequada em relação à destinação dos resíduos sólidos, sem contar o tamanho impacto social de indivíduos sobrevivendo em condições indignas. Portanto, esta atividade permitiu que os participantes percebessem a posição de 
Ensino, Saúde e Ambiente - V12 (3), pp. 202-216, Dez. 2019

outros papéis, assim como a complexidade da situação tratada, sendo uma oportunidade de experimentar uma situação bastante real que estes profissionais podem se deparar no exercício de suas profissões.

\section{REFERÊNCIAS}

ACSELRAD, H.; MELLO, C. C. A.; BEZERRA, G. N. O que é Justiça Ambiental? Rio de Janeiro: Garamond, 2009.

ALBUQERQUE, C.; VICENTINI, J. O.; PIPITONE, M. A. P. O Júri simulado como prática para a educação ambiental crítica. Revista Brasileira de Estudos Pedagógicos, Brasília, v. 96, n. 242, p. 199-215, 2015.

ALBUQUERQUE, F. M. A. S; FARIAS, C. R. O.; ARAÚJO, M. L. O uso educativo do júri simulado no ensino médio: estratégias para o estudo de uma temática socioambiental controversa. In: XIII Jornada de Ensino, Pesquisa e Extensão (JEPEX), 9 a 13 de dezembro de 2013, Recife, Anais... Recife: UFRPE, 2013.

BARDIN, L. Análise de conteúdo. Lisboa: Edições Setenta, 2008.

BENVINDO, A. Z. A nomeação no processo de construção do catador como ator econômico e social. 2010. 95f. Dissertação (Mestrado em Ciências Sociais) - Universidade de Brasília, Brasília, 2010.

BERBEL, N. A. N. As metodologias ativas e a promoção da autonomia de estudantes. Semina: Ciências Sociais e Humanas, Londrina, v. 32, n. 1, p. 25-40, 2011.

BERNARDO, J. R. R.; VIEIRA, R. D.; MELO, V. F. O júri simulado sobre questões sociocientíficas e a alternância de papéis: contribuições para o desenvolvimento de habilidades argumentativas de professores. In: GALIETA, T.; GIRALDI, P. M. (Org.) Linguagens e discursos na educação em ciências. Rio de Janeiro: Multifoco, 2014. p. 360374.

BOSI, A. P. A organização capitalista do trabalho "informal": o caso dos catadores de recicláveis. Revista Brasileira de Ciências Sociais, São Paulo, v.23, n.67, p.101-116, 2008.

CAMPOS, M.; SILVEIRA, M. Do planejamento à ação: elaboração de dinâmicas de trabalho em grupo em ambientes virtuais como estratégia à mediação e interação. In: CARNEIRO, M.L.; TURCHIELO, L.B. Educação a distância e tutoria: considerações pedagógicas e práticas. Porto Alegre: Evangraf, 2013. p. 74-94.

CARMO, W. F. S. A.; FREITAS, E. D.; ALVES, W. A.; NUNES, L. C. "Júri simulado" como estratégia de reflexão de um desastre ambiental, no ensino médico de uma Instituição Pública de Ensino Superior do Leste de Minas Gerais. JMPHC (Journal of Management and Primary Health Care), Recife, v. 7, n. 1, p. 25, 2016.

CATAPRETA C. A. A.; HELLER L. Associação entre coleta de resíduos sólidos domiciliares e saúde, Belo Horizonte (MG), Brasil. Revista Panamericana de Salud Pública,

Washington, v. 5, p. 88-96, 1999. 
Ensino, Saúde e Ambiente - V12 (3), pp. 202-216, Dez. 2019

DEMAJOROVIC, J.; SILVA, H. C. Oliveira da. Formação interdisciplinar e sustentabilidade em cursos de administração: desafios e perspectivas. RAM: Revista de Administração Mackenzie, São Paulo, v.13, n.5, p.39-64, 2012.

DOMINGO, J. L.; NADAL, M. Domestic waste composting facilities: a review of human health risks. Environment International, Lancaster, v. 35, p. 382-389, 2009.

FERRAZ, L.; GOMES, M. H. A.; BUSATO, M. A. O catador de materiais recicláveis: um agente ambiental. Cadernos EBAPE.BR, Rio de Janeiro, v. 10, n. 3, opinião 5, p. 763-768, set. 2012.

FREIRE, P. Pedagogia do oprimido. 17ª ed. Rio de Janeiro, Paz e Terra, 1987.

GASKELL, G. Entrevistas individuais e grupais. In: BAUER, M. W.; GASKELL, G. (orgs.). Pesquisa qualitativa com texto, imagem e som: um manual prático. 6. ed. Petrópolis: Vozes, p. 64-89; 2007.

GIDDENS, A. As consequências da Modernidade. São Paulo: UNESP, 1990.

GUERRA, A. F. S. et al. A ambientalização na Educação Superior: trajetória e perspectivas. GUERRA, A. F. S. (Org.). Ambientalização e Sustentabilidade nas Universidades: subsídios, reflexões e aprendizagens. Itajaí: Editora da Univali, 2015. pp. 11-33.

MARTíneZ-AliER, J. O Ecologismo dos Pobres. 2 ed. São Paulo: Contexto, 2014.

MCSHARRY, G.; JONES, S. Role-play in Science Teaching and Learning. School Science Review, Herts, v.82, n. 298, p. 73-82, 2000.

MEDEIROS, L. F. R.; TEIXEIRA, M. A. C. Catador de material reciclável: uma profissão para além da sobrevivência? Psicologia e Sociedade, Belo Horizonte, v. 18, n. 2, p. 62-71, ago., 2006.

MOTTA, G. M. V., BORGES, L. O. Limpeza urbana: o contexto institucional e a atividade de varrição em belo horizonte. Revista Psicologia Organizações e Trabalho, Florianópolis, v. 14, n. 1, p. 37-51, 2014.

NEWTON, D. E. Environmental Justice: a reference handbook. 2. ed. Santa Barbara, California: ABC-CLIO, 2009.

PORTA D.; MILANI, S.; LAZZARINO, A. I.; PERUCCI, C. A.; FORASTIERE, F. Systematic review of epidemiological studies on health effects associated with management of solid waste. Environmental Health, Londres, v. 8, n. 60, 2009.

PORTO, M. F. S.; JUNCÁ, D. C. M.; GONÇALVES, R. S.; FILHOTE, M. I. F. Lixo, trabalho e saúde: um estudo de caso com catadores em um aterro metropolitano no Rio de Janeiro, Brasil. Cadernos de Saúde Pública, Rio de Janeiro, v. 20, n. 6, p. 1503-1514, novdez, 2004.

REAL, L. M. C.; MENEZES, C. Júri simulado: possibilidade de construção de conhecimento a partir de interações em um grupo. In: NEVADO, R.A.; CARVALHO, M.J.S.; MENEZES, C.S. (Org.). Aprendizagem em rede na Educação a Distância: estudos e recursos para formação de professores. Porto Alegre: Ricardo Lenz, 2007. p. 85-94.

REIS, P. R. Os temas controversos na educação ambiental. Pesquisa em Educação Ambiental, Rio Claro, v. 2, n. 1, p. 125-140, 2007. 
Ensino, Saúde e Ambiente - V12 (3), pp. 202-216, Dez. 2019

RUSHTON, L. Health hazards and waste management. British Medical Bulletin, Oxford, v. 68, p. 183-97, 2003.

SHRADER-FRECHETTE, K. S. Environmental Justice: creating equality, reclaiming democracy. Nova York: Oxford University Press, 2002.

SIQUEIRA, M. M.; MORAES, M. S. Saúde coletiva, resíduos sólidos urbanos e os catadores de lixo. Ciência \& Saúde Coletiva, Rio de Janeiro, v. 14, n. 6, p. 2115-2122, dez., 2009.

VIÉGAS, R. N., PINTO, R. G., GARZON, L. F. N. Negociação e acordo ambiental: o Termo de Ajustamento de Conduta (TAC) como forma de tratamento dos conflitos ambientais. Rio de Janeiro: Fundação Heinrich Böll, 2015.

VIEIRA, R. D.; BERNARDO, J. R. R.; EVAGOROU, M.; MELO, V. F. Argumentation in Science Teacher Education: The simulated jury as a resource for teaching and learning.

International Journal of Science Education, Victoria, v. 37, n. 7, p. 1113-1139, 2015.

VIEIRA, R. D.; MELO, V. F.; BERNARDO, J. R. R. O Júri simulado como recurso didático para promover argumentações na formação de professores de física: o problema do "gato".

Ensaio: Pesquisa em Educação em Ciências, Belo Horizonte, v. 16, n. 3, p. 203-225, 2014.

\section{SOBRE OS AUTORES}

\section{Marcos Paulo Gomes Mol}

Formado em engenharia ambiental pela Universidade Federal de Ouro Preto, Mestre e Doutor em Saneamento e Meio Ambiente pela Universidade Federal de Minas Gerais (UFMG). Foi coordenador da Unidade de Gestão Ambiental da Fundação Ezequiel Dias (Funed) em Belo Horizonte (2007 a 2015) e, atualmente, é pesquisador da Funed, coordenando o grupo de pesquisa Saúde e Meio Ambiente, credenciado no CNPQ.

\section{Valdir Lamim Guedes Junior}

Biólogo e Mestre em Ecologia pela Universidade Federal de Ouro Preto, Especialista em Jornalismo Científico (UNICAMP), Educação Ambiental (USP-SC) e em design Instrucional para EaD (UNIFEI), Doutor em Educação pela USP. É professor de graduação e pósgraduação no Centro Universitário Senac-Santo Amaro (São Paulo-SP). 